\title{
Effect of composition changes and aeration time on the structure and rehydration of innovative freeze-dried gels**
}

\author{
Agnieszka Ciurzyńska*, Agata Pisarska, Ignacy Olsiński, Anna Maria Panfiluk, Magdalena Sylwia Ostap, \\ and Andrzej Lenart
}

\begin{abstract}
Faculty of Food Sciences, Department of Food Engineering and Process Management, Warsaw University of Life Sciences, SGGW, Nowoursynowska 159c, 02-776 Warsaw, Poland
\end{abstract}

Received April 24, 2017; accepted December 29, 2017

\begin{abstract}
This paper seeks to explain the structural effect on selected properties of freeze-dried gels with different compositions and aeration times. Herein, sugars and citric acid were added to gels with low-methoxyl pectin, mixtures of xanthan gum and locust bean gum, as well as xanthan gum and guar gum, in order to obtain a strawberry model. Strawberry pulp was also added to hydrocolloids to develop an innovative strawberry product. All samples were aerated for 3 and $7 \mathrm{~min}$, and freezedried. Composition changes were found to modify the structure of the examined samples and properties. Freeze-dried gels with low-methoxyl pectin seemed to reflect the best approach towards obtaining an innovative strawberry product with a tailored structure, as they had the best water absorbent capacity, and the most attractive and delicate structure. Samples with a mixture of hydrocolloids were more compact. Aeration time did not significantly affect the examined parameters, while the addition of sugar and citric acid increased them. The strawberry pulp experiment confirmed the strawberry model (with low-methoxyl pectin gels, and sugar and citric acid), which had the finest structure and the best rehydration properties.

Keyw ords: aeration, hydrocolloids, structure, sugar, rehydration, strawberry pulp
\end{abstract}

\section{INTRODUCTION}

Consumers, and in particular young people, are increasingly looking for innovative products and food which is healthy and easy to prepare (Martin-Esparza et al., 2011). Aerated food is very popular, and yet people are not aware

*Corresponding author e-mail: agnieszka_ciurzynska@sggw.pl **This work was funded by the National Science Centre on the grounds of Decision No. DEC-2013/09/D/NZ9/04150 (20142017) and was also co-financed by a statutory activity subsidy from the Polish Ministry of Science and Higher Education for the Faculty of Food Sciences of Warsaw University of Life Sciences (2017-2018). that many food products they consume actually contain air bubbles (Aguilera, 2005). Such food is not only attractive to the senses but also healthy, as a result of reduced calorific content (Palzer, 2009; Valenzuela and Aguilera, 2013). In researching the physical properties of food, gels may be used as food models (Nussinovitch et al., 1993), but the relationship between the recipe of the food model and the method of gas dispersion in a gel matrix is of key importance (Labbafi et al., 2007). Nussinovitch et al. (2001) pointed out that the preparation conditions and composition (e.g. sugar added to hydrocolloid matrix) play important roles in creating controlled microstructures and properties (Nussinovitch et al., 2000, 2001).

Although fruit is appreciated due to its composition, including especially the content of minerals, vitamins, and antioxidants, its consumption is still below WHO recommendations. Strawberries are a fruit with a rich composition but a short shelf life. Fruit in the form of pulp may be used to develop innovative products based on hydrocolloids. Such products are attractive because of the significant effect of actual fruit content on gel matrix, and also because of such sensory characteristics as taste and colour. The creation of attractive microstructures in such products is possible due to the use of freeze-drying for gel solidifying (Valenzuela and Aguilera, 2013).

The aim of this work is to study the structural and physical properties of freeze-dried hydrocolloid gels with diverse composition and aeration time, when sugar and citric acid (in the strawberry model) or strawberry pulp are added to the constituents.

(C) 2018 Institute of Agrophysics, Polish Academy of Sciences 


\section{MATERIALS AND METHODS}

The recipe for hydrocolloid gels with amidated lowmethoxyl pectin (LMP) (degree of amidation 18-23\%, and degree of esterification 27-32 \%), a mixture of xanthan gum and locust bean gum $(\mathrm{KG}+\mathrm{LBG})$, and a mixture of xanthan gum and guar gum $(\mathrm{KG}+\mathrm{GG})$, developed in the course of previous research (Ciurzyńska and Lenart, 2016), was modified by the addition of sugars (crystal sucrose - Sugar Factory Glinojeck S.A., Poland; crystal glucose with $8 \%$ of water content - JAR manufacturer, Jaskulski Flavors, Poland), and citric acid (Hortimex Company, Poland) in order to obtain a strawberry model. The exact process of sample preparation was described by Ciurzyńska et al. (2017). Freeze-dried strawberry gels with strawberry pulp (thawed strawberry of the Honey variety), replacing the sugars and citric acid used in the strawberry model recipe, were also obtained. Herein, the strawberry pulp was heated to $\sim 70{ }^{\circ} \mathrm{C}$, and hydrocolloids mixed with water were added to the pulp. The mixture was aerated for 3 and $7 \mathrm{~min}$, cut into cubes $\left(1 \mathrm{~cm}^{2}\right)$ after gelation, frozen (the freezer chamber temperature being $-45^{\circ} \mathrm{C} 2 \mathrm{~h}^{-1}$ ), and freeze-dried (at 63 $\mathrm{Pa} / 30^{\circ} \mathrm{C} / 24 \mathrm{~h}$ ).

Recipes for the aforementioned freeze-dried hydrocolloid gels are summarised in Table 1.

The structure was studied with the use of a scanning electron microscope TM-3000 HITACHI for $1 \mathrm{~mm}$-thick slices cut from the freeze-dried cubes along their axis (magnification 50x).

Water activity was measured in triplicate for every sample, using the Rotronic Higroscope DT, according to the manufacturer's instruction.
Shrinkage was determined according to the method developed by Ciurzyńska and Lenart (2016). The measurement allowed for an estimation of the real density value.

Rehydration property determination involved holding freeze-dried gel cubes in water $\left(20^{\circ} \mathrm{C}\right)$ for 5 and $120 \mathrm{~min}$ in three iterations. After $120 \mathrm{~min}$ of rehydration, the water content was determined for comparison with the values obtained for the gel samples prior to freeze-drying (Ciurzyńska and Lenart, 2012).

The statistical analysis was conducted with the Statgraphic Plus, version. 4.1. and Excel 2010 software (Microsoft) and the Fisher test was applied to verify the hypothesis on the equality of the mean values of the analyzed coefficients (a significance level of 0.05).

\section{RESULTS AND DISCUSSION}

The addition of sugars and citric acid modified the structure of the freeze-dried hydrocolloid gels (LMP, KG+LBG, $\mathrm{KG}+\mathrm{GG} 3 \mathrm{~A}, 7 \mathrm{~A}$ ) (Fig. 1), as compared to samples without such ingredients (obtained and described previously by Ciurzyńska and Lenart (2016)). The structure became more compact, while the pores created during the aeration and freeze-drying process were smaller and more irregular in shape (preventing the proper measurement of pore diameters). Such changes were confirmed via shrinkage and real density measurements (Figs 2 and 3). The most attractive structure of the strawberry models was that with low-methoxyl pectin (LMP 3A, 7A), in comparison to samples with a hydrocolloid mixture. This may be related to the pectin properties obtained after the addition of sugar. Fu and Rao (2001) showed that sucrose, when added to low-methoxyl

Table 1. Composition and symbol of freeze-dried gels. Aeration time: 3 and $7 \mathrm{~min}$

\begin{tabular}{|c|c|c|c|c|c|}
\hline Sample symbol & Hydrocolloids content & $\begin{array}{l}\text { Sugars and citric acid } \\
\text { content or strawberry } \\
\text { pulp }\end{array}$ & $\mathrm{pH}$ & $\begin{array}{c}\text { Freezing } \\
\text { (temp/time) }\end{array}$ & $\begin{array}{l}\text { Freeze-drying } \\
\text { (temp/time) }\end{array}$ \\
\hline \multicolumn{6}{|c|}{ Strawberry model (A) } \\
\hline $\begin{array}{l}\text { LMP 3A } \\
\text { LMP 7A }\end{array}$ & $\begin{array}{l}\text { Low-methoxyl pectin } 2.5 \% \\
\text { Calcium lactate } 0.15 \%\end{array}$ & & 3.80 & & \\
\hline $\begin{array}{l}\mathrm{KG}+\mathrm{LBG} 3 \mathrm{~A} \\
\mathrm{KG}+\mathrm{LBG} 7 \mathrm{~A}\end{array}$ & $\begin{array}{l}\text { Xanthan gum } 2 \% \\
\text { Locust bean gum 1.5\% }\end{array}$ & $\begin{array}{c}\text { Glucose } 6.8 \% \\
\text { Sucrose } 1 \% \\
\text { Citric acid } 0.64 \%\end{array}$ & 3.90 & & \\
\hline $\begin{array}{l}\mathrm{KG}+\mathrm{GG} 3 \mathrm{~A} \\
\mathrm{KG}+\mathrm{GG} 7 \mathrm{~A}\end{array}$ & $\begin{array}{l}\text { Xanthan gum } 2 \% \\
\text { Guar gum } 2 \%\end{array}$ & & 3.72 & $\left(-45^{\circ} \mathrm{C} / 2 \mathrm{~h}\right)$ & $30^{\circ} \mathrm{C} / 24 \mathrm{~h}$ \\
\hline \multicolumn{6}{|c|}{ Strawberry gel (B) } \\
\hline $\begin{array}{l}\text { LMP 3B } \\
\text { LMP 7B }\end{array}$ & $\begin{array}{l}\text { Low-methoxyl pectin } 2.5 \% \\
\text { Calcium lactate } 0.15 \%\end{array}$ & & 3.62 & & \\
\hline $\begin{array}{l}\mathrm{KG}+\mathrm{LBG} 3 \mathrm{~B} \\
\mathrm{KG}+\mathrm{LBG} 7 \mathrm{~B}\end{array}$ & $\begin{array}{l}\text { Xanthan gum } 1.5 \% \\
\text { Locust bean gum } 1 \%\end{array}$ & Strawberry pulp $\quad 87 \%$ & 3.51 & & \\
\hline $\begin{array}{l}\mathrm{KG}+\mathrm{GG} 3 \mathrm{~B} \\
\mathrm{KG}+\mathrm{GG} 7 \mathrm{~B}\end{array}$ & $\begin{array}{l}\text { Xanthan gum } 1.5 \% \\
\text { Guar gum } 1.5 \%\end{array}$ & & 3.52 & & \\
\hline
\end{tabular}


a
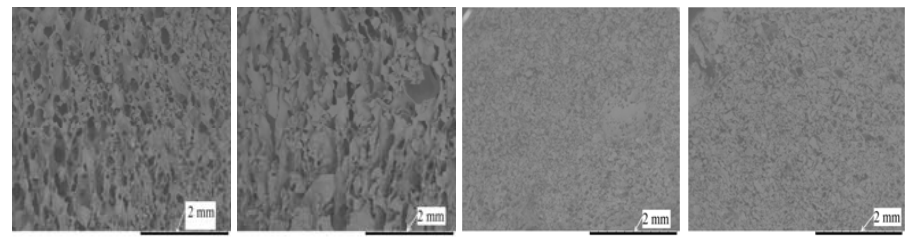

b
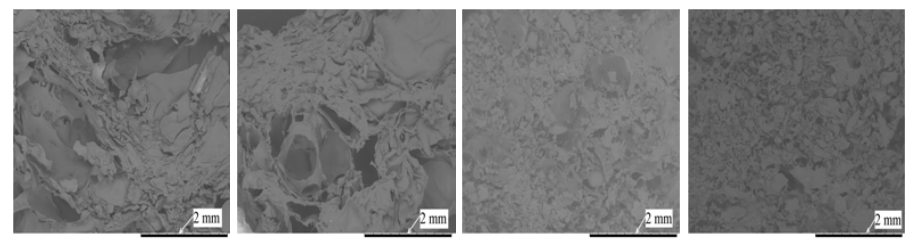

c
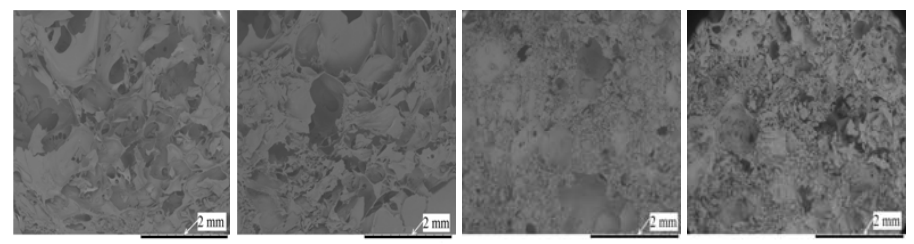

A

A

B

B

$3 \min$

$7 \mathrm{~min}$

$3 \mathrm{~min}$

$7 \mathrm{~min}$

Fig. 1. Structure of freeze-dried gels with: $a$ - low-methoxyl pectine (LMP), b - mixture of xanthan gum and locust bean gum $(\mathrm{KG}+\mathrm{LBG}), \mathrm{c}-$ mixture of xanthan gum and guar gum $(\mathrm{KG}+\mathrm{GG})$. Composition: A - sugars and citric acid addition, B - strawberry pulp addition. Aeration time: 3 and 7 min. Magnification 50x.

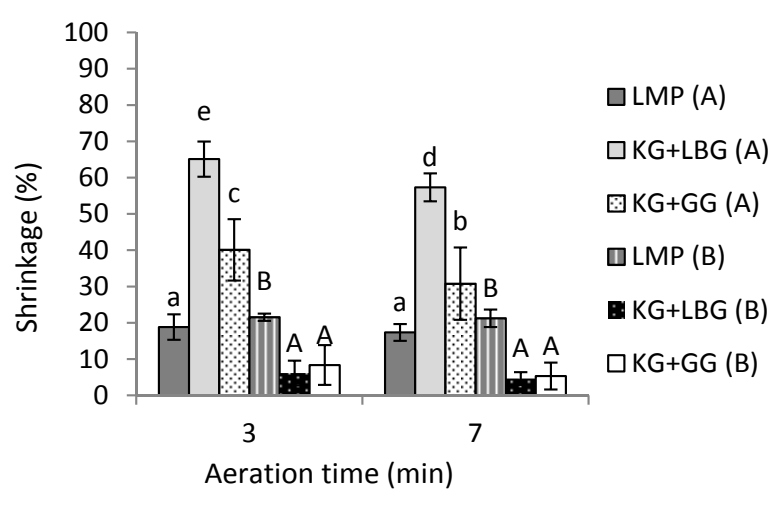

Fig. 2. Shrinkage of aerated freeze-dried gels with different aeration time and composition: A - sugars and citric acid addition, B - strawberry pulp addition, LMP - low-methoxyl pectine, $\mathrm{KG}+\mathrm{LBG}$ - mixture of xanthan gum and locust bean gum, $\mathrm{KG}+\mathrm{GG}-$ mixture of xanthan gum and guar gum. The values are mean $(n=6) \pm S E$. Means followed by the same letter in the bar diagram are not significantly different according to ANOVA and Fisher multiple comparison tests. Designation of samples Table 1. pectin gels, was likely to stabilize the structure of crossing areas due to the development of hydroxyl groups. The structure of LMP, $\mathrm{KG}+\mathrm{LBG}, \mathrm{KG}+\mathrm{GG}$ gels, aerated for 3 and $7 \mathrm{~min}$ and with strawberry pulp added, became finer, and many of the air bubbles introduced during the aeration process formed small empty spaces after freeze-drying (Fig. 1). As a result, the strawberry pulp sample structures were more evenly aerated, in comparison to the gels which were obtained via the strawberry model. In addition, microscopic photos showed that areas of bigger empty spaces (pores) appeared in the samples with a mixture of xanthan gum and guar gum $(\mathrm{KG}+\mathrm{GG} 3 \mathrm{~B}, 7 \mathrm{~B})$. These were probably created as an effect of breaking apart the bigger air bubbles generated during the freeze-drying process.

Freeze-dried gels (strawberry models with sugar and citric acid, as well as gels with strawberry pulp) were characterized by low water activity values in the range of 0.14-0.33 (Table 2), similar to the water activity for freezedried strawberries (Piotrowski et al., 2008). Such results confirm the observations made by Sankat and Castaigne (2004), who claimed that foaming agents added to aerated samples help to remove moisture during the drying process 


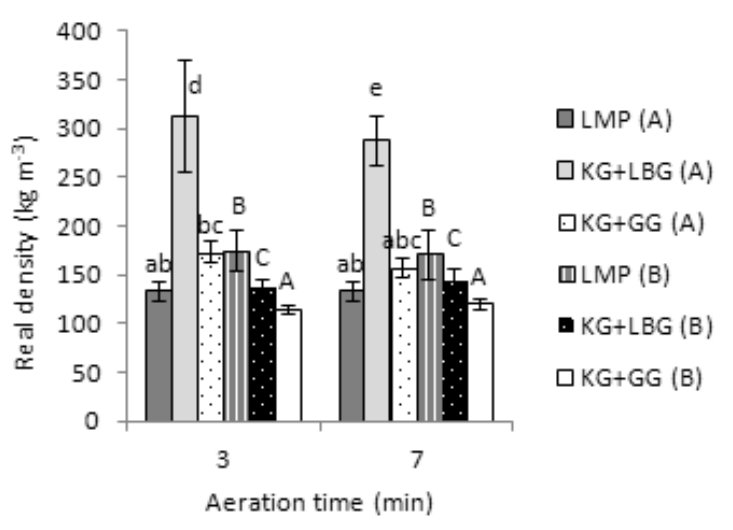

Fig. 3. Real density of aerated freeze-dried gels with different addition time and composition. The values are mean $(n=6) \pm S E$. Explanations as in Fig. 2. content, size and distribution of 'air bubbles' in the material are the most important parameters which determine the properties of aerated foods, but they are also difficult to control. Aeration time, the material quality, the recipe and gas dispersion are interconnected. Van Aken (2001) pointed out that small air bubbles are incorporated into, e.g., cream during whipping and are stabilized by a layer of absorbed emulsion, but the effectiveness of air incorporation at the first stage of whipping is the main factor which determines product properties.

Sugars and citric acid, when added to hydrocolloids in order to obtain the strawberry model, increased the shrinkage of freeze-dried hydrocolloid gels (19-65\%) (Fig. 2) and their real density (133-312 $\mathrm{kg} \mathrm{m}^{-3}$ ) (Fig. 3), in comparison to the samples without sugars and citric acid that were investigated and described previously by Ciurzyńska and

Table 2. Water activity after freeze-drying, water content before freeze-drying and after 120 min of rehydration, of aerated freezedried gels with different composition and aeration time. The values are mean ( $\mathrm{n}=6$ for water activity and $\mathrm{n}=9$ for water content) $\pm \mathrm{SE}$. The means followed by same letter are not significantly different

\begin{tabular}{lccc}
\hline \multirow{2}{*}{ Sample symbol } & $\begin{array}{c}\text { Water activity } \\
\left(\mathrm{a}_{\mathrm{w}}\right)\end{array}$ & \multicolumn{2}{c}{ Water content } \\
\cline { 3 - 4 } LMP 3A & $0.22 \pm 0.01 \mathrm{a}$ & $87.52 \pm 1.08 \mathrm{a}$ & after rehydration $(\%)$ \\
LMP 7A & $0.22 \pm 0.01 \mathrm{a}$ & $87.14 \pm 0.25 \mathrm{abc}$ & $96.67 \pm 0,69 \mathrm{c}$ \\
KG+LBG 3A & $0.29 \pm 0.01 \mathrm{~b}$ & $86.71 \pm 0.35 \mathrm{a}$ & $97.26 \pm 0.81 \mathrm{c}$ \\
KG+LBG 7A & $0.31 \pm 0.01 \mathrm{c}$ & $87.06 \pm 0.97 \mathrm{abcd}$ & $93.50 \pm 1.48 \mathrm{~b}$ \\
KG+GG 3A & $0.32 \pm 0.01 \mathrm{~d}$ & $85.12 \pm 1.55 \mathrm{f}$ & $93.93 \pm 0.89 \mathrm{~b}$ \\
KG+GG 7A & $0.33 \pm 0.00 \mathrm{~d}$ & $86.48 \pm 0.44 \mathrm{cde}$ & $90.29 \pm 1.13 \mathrm{a}$ \\
& & & $90.79 \pm 1.24 \mathrm{a}$ \\
LMP 3B & $0.17 \pm 0.00 \mathrm{D}$ & $84.06 \pm 0.27 \mathrm{DEF}$ & $97.71 \pm 0.21 \mathrm{ABC}$ \\
LMP 7B & $0.14 \pm 0.01 \mathrm{C}$ & $84.33 \pm 0.22 \mathrm{CD}$ & $92.46 \pm 0.20 \mathrm{CD}$ \\
KG+LBG 3B & $0.26 \pm 0.03 \mathrm{D}$ & $83.60 \pm 0.40 \mathrm{~F}$ & $92.11 \pm 0.57 \mathrm{BCD}$ \\
KG+LBG 7AB & $0.24 \pm 0.01 \mathrm{C}$ & $84.05 \pm 0.33 \mathrm{DEF}$ & $92.46 \pm 0.20 \mathrm{BCD}$ \\
KG+GG 3B & $0.20 \pm 0.02 \mathrm{~B}$ & $86.27 \pm 0.21 \mathrm{~A}$ & $91.09 \pm 0.85 \mathrm{~A}$ \\
KG+GG 7B & $0.18 \pm 0.01 \mathrm{~A}$ & $86.11 \pm 0.22 \mathrm{~A}$ & $92.46 \pm 0.20 \mathrm{ABCD}$ \\
\hline
\end{tabular}

and create open structural effects. It was also shown that the aeration time prolongation significantly decreased the water activity of freeze-dried gels with strawberry pulp, but for most of investigated properties, the effect of aeration time ( 3 or $7 \mathrm{~min}$ ) on the properties was insignificant. This indicates that the structure (Fig. 1) is created more during the freezing and freeze-drying process than during aeration. Such effect was confirmed previously by Ciurzyńska et al. (2017). While the achieved delicate structure may change during the drying process (Labbafi et al., 2007), freeze-drying is considered the best method of producing high-quality aerated gel products (Ceballos et al., 2012; Ratti, 2001). Nussinovitch et al. (2001) found that various structures of solid sponges may be affected by freezing rates and aeration. What is more, Labbafi et al. (2007) pointed out that the
Lenart (2016), who obtained the shrinkage values in the range of (3-38\%) and density $2-30 \mathrm{~kg} \mathrm{~m}^{-3}$. The shrinkage values obtained for the strawberry model with low-methoxyl pectin (LMP 3A, 7A) were also similar to the shrinkage values for freeze-dried strawberries (16-23\%) investigated by Raghavan and Silveira (2001).

The effect of aeration time ( 3 or $7 \mathrm{~min}$ ) for gels with low-methoxyl pectin, and for sugars and citric acid (LMP $3 \mathrm{~A}, 7 \mathrm{~A}$ ), was insignificant, whereas the elongation of aeration time from 3 to $7 \mathrm{~min}$ for gels with a mixture of hydrocolloids decreased the shrinkage value. Nussinovitch et al. $(2000,2001)$ also obtained an increase in the apparent density for dried gels with sugar added. The addition of oil to hydrocolloid gels was also found to change the structure of freeze-dried samples. These became more 
compact because their pores were smaller, which increased their density (Nussinovitch and Gershon, 1997). The highest shrinkage value (57-65\%), obtained for samples with a mixture of xanthan gum and locust bean gum, as well as sugars and citric acid (KG+LBG 3A, 7A), was thought to be the effect of structural collapse. This was confirmed by observations of the structure (Fig. 1b).

For samples with low-methoxyl pectin and strawberry pulp (LMP 3B, 7B), the shrinkage value was higher, but it was similar to the values obtained for the strawberry model samples (LMP 3A, 7A). The addition of strawberry pulp to the mixture of hydrocolloids significantly decreased the freeze-dried gels shrinkage value in comparison to the strawberry model samples with the addition of sugars and citric acid (Fig. 2). The actual aeration time was, however, insignificant for all freeze-dried gel samples with strawberry pulp. Still, with a decrease of shrinkage, real density also decreased (Fig. 3). Furthermore, the strengthened structure of samples $\mathrm{KG}+\mathrm{LBG}, \mathrm{KG}+\mathrm{GG}$, which were aerated for 3 and 7 minutes and with the addition of strawberry pulp, was more resistant to damage during the freezing and freezedrying process. Therefore, no adverse changes (significant shrinkage) were observed, as in the case of strawberry models.

Several researchers (Mc Minn and Magee, 1997; Prothon, 2003) claim that determining the ability of the material to maintain and bind water during rehydration is an appropriate way of estimating the extent of tissue destruction. In our work, the rehydration properties of the investigated freeze-dried gels confirmed the shrinkage results. For the strawberry model with low-methoxyl pectin (LMP 3A, 7A), the lowest shrinkage effect on the rehydration ability increased after 5 and 120 min of rehydration (Fig. 4), as compared to the samples containing a mixture of hydrocolloids ( $\mathrm{KG} \mathrm{3A}, 7 \mathrm{~A}+\mathrm{LBG}$ and $\mathrm{KG}+\mathrm{GG} 3 \mathrm{~A}, 7 \mathrm{~A}$ ). What is more, after 120 min of rehydration, LMP 3A, 7A samples obtained the highest water content value (Table 2). Samples with a mixture of hydrocolloids, $(\mathrm{KG}+\mathrm{LBG} 3 \mathrm{~A}$,
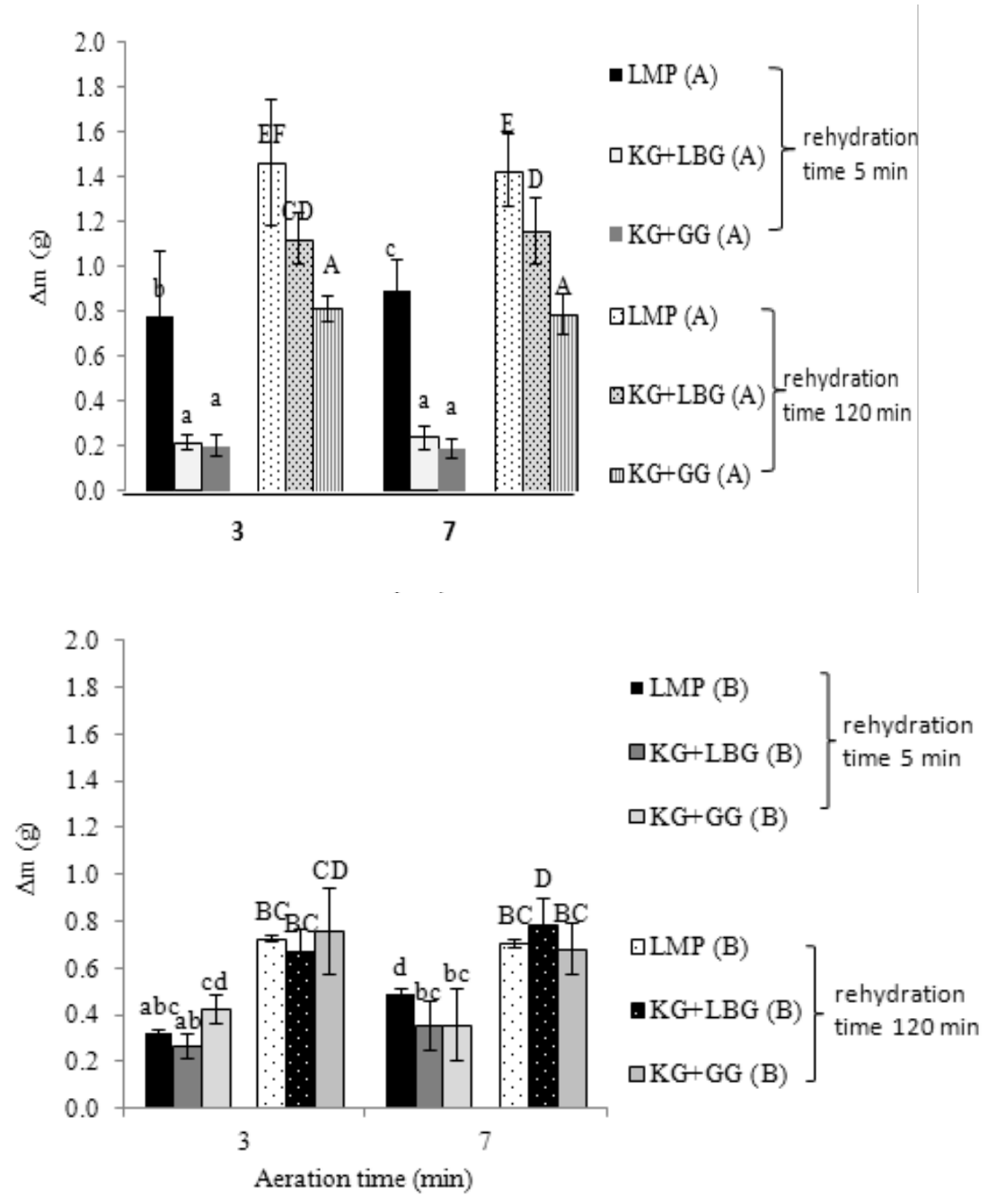

Fig. 4. Rehydration properties (mas increase $-\Delta \mathrm{m}$ ) of aerated freeze-dried gels with different addition time and composition. Values are mean $(\mathrm{n}=9) \pm$ SE. Explanations as in Fig. 2. 
7A) and (KG+GG 3A, 7A) were characterised by higher shrinkage and density values (Figs 2 and 3). These result in a decrease in water absorption during the rehydration process (Fig. 4). Such properties relate to the structure of the samples (Fig. 1b, c). Before the freeze-drying process, gels with a mixture of xanthan gum and locust bean gum, and with added sugars and citric acid $(\mathrm{KG}+\mathrm{LBG} 3 \mathrm{~A}, 7 \mathrm{~A})$ were characterized by a high amount of air bubbles entrapped within the gel matrix. Such structure was very delicate and prone to damage during the freeze-drying process, therefore, adverse shrinkage occurred and the structure was found to be the most compact (Fig. 1b). Based on the studies of different properties conducted for samples with a mixture of xanthan gum and guar gum $(\mathrm{KG}+\mathrm{GG} 3 \mathrm{~A}, 7 \mathrm{~A}$ ) (not presented here) and the aforementioned structural observations, it is hypothesised that free spaces in such freeze-dried gels are filled with sugar, but the created structure is softer than that for samples with a mixture of xanthan gum and locust bean gum (KG+LBG 3A, 7A) (Fig. 1c).

The addition of sugars and citric acid to hydrocolloids increased the rehydration capacity of freeze-dried strawberry models. This mainly concerned samples with low-methoxyl pectin (LMP 3A, 7A) (Fig. 4, Table 2), in comparison to the results for samples without the sugars and acid addition described previously by Ciurzyńska and Lenart (2016). This result was unexpected, because it was assumed that shrinkage would be the most important factor to influence a decrease in the rehydration capacity (compared to gels without the addition of sugars and citric acid). Thus, the introduction of sugar and acid had probably changed the mechanism of water absorption by the structure. Lewicki et al. (1997) explained that the collapse seen at the end of the drying process may result from the emergence of an amorphous domain, which is the region most available for water during rehydration. Amorphous regions are rehydrated fast, but their crystalline structures are resistant to solvation. Therefore, tension in the material increases during rehydration. At the beginning of the rehydration process, the structure cannot resist stresses and the matrix swells due to the absorption of water by polymers and other ingredients.

Thibault and Ralet (2003) argued that the particle size may have an impact on rehydration properties, given that smaller samples have lower rehydration properties, possibly because of modifications in the structural regions that previously bound and held water.

The obtained results may also confirm the importance of additives because sugars, which are frequently added to different food products, may increase the rehydration ability and influence texture properties of such foods. Examples of such additives are freeze-dried agar and gellan gels (Nussinovitch et al., 2000). A similar sugar addition effect was observed in pineapple slices osmotically dehydrated in a sugar solution, whereby the rehydration ability increased in comparison to the samples without osmotic pre-treatment before the drying process (Fasogbon et al., 2013).

Nussinovitch et al. (2000) explained that the stoichiometric relationships for different ingredients, e.g. gum, and other additives, are difficult to predict but such interactions may influence the properties and structure of the dry solid matrix. Such phenomenon may have occurred in the strawberry pulp addition samples because of the insignificant shrinkage increase for LMP 3B, 7B samples, in comparison to samples with sugars and citric acid addition (LMP 3A, 7A). Such samples saw a 50\% rehydration decrease (Fig. 4). For samples with strawberry pulp and a hydrocolloid mixture $(\mathrm{KG}+\mathrm{LBG} 3 \mathrm{~B}, 7 \mathrm{~B}$ and $\mathrm{KG}+\mathrm{GG} 3 \mathrm{~B}, 7 \mathrm{~B}), 40-60 \%$ shrinkage decrease was noted (Fig. 2), in comparison to strawberry model samples (KG+LBG 3A, 7A and $\mathrm{KG}+\mathrm{GG}$ $3 \mathrm{~A}, 7 \mathrm{~A})$. Furthermore, we saw a slight increase in the mass after 5 min of rehydration, along with a decrease in the rehydration ability after 120 min of hydration. Van Aken (2001) explained that changes in the regions of pectin-rich fibres, which previously absorbed and held water, may reduce the particle size and the same decreased hydration ability.

All freeze-dried gels after rehydration (120 min) obtained higher water content values, in comparison to samples before freeze-drying (Table 2). This may indicate that water was absorbed not only by the porous structure of the freeze-dried gels, but also by the hydrocolloids which bind the water.

\section{CONCLUSIONS}

1. A strawberry model was developed in the form of aerated freeze-dried gels with sugar and citric acid additives by way of the mechanical whipping of different hydrocolloids used as foaming agents.

2. Freeze-dried gels with low-methoxyl pectin seem to be the best way to obtain an innovative strawberry product with the designed structure, as they absorb the majority of the contained water. This effect is related to the structure, the lowest shrinkage and real density.

3. Samples with a mixture of hydrocolloids proved to be more compact. Moreover, the highest shrinkage and real density values were obtained for samples with a mixture of xanthan gum and locust bean gum. Finally, the rehydration properties were the lowest, as previously expected. Aeration time did not significantly affect the examined parameters, while sugar and acid additives increased aeration time, in comparison to the samples investigated and described previously. This effect is related to structure changes.

4. Although samples with the strawberry pulp addition, and with a mixture of xanthan gum and guar gum, showed similar properties to strawberry gels with low-methoxyl pectin, the gel structure before freeze-drying was characterized by a low value of gelation and the cubic shape was difficult to maintain. This is the most important reason why 
low-methoxyl pectin is preferred for the industrial production of freeze-dried strawberry gels. The varied structure of freeze-dried gels with a mixture of hydrocolloids has an impact on the rehydration ability decrease, as compared to pectin gels alone.

5. It was confirmed that samples with low-methoxyl pectin and strawberry pulp were superior, as their structure proved to be the finest and remained the highest even though shrinkage, and the rehydration properties were the best. Finally, such a product is healthy, as it contains $87 \%$ of strawberry pulp.

Conflict of interest: The Authors do not declare conflict of interest.

\section{REFERENCES}

Aguilera J.M., 2005. Why food microstructure? J. Food Eng., 67(1-2), 3-11.

Ceballos A.M., Giraldo G.I., and Orrego C.E., 2012. Effect of freezing rate on quality parameters of freeze dried soursop fruit pulp. J. Food Eng., 111(2), 360-365.

Ciurzyńska A. and Lenart A., 2012. Erratum: Rehydration and sorption properties of osmotically pretreated freeze-dried strawberries. J. Food Eng., 113, 361.

Ciurzyńska A. and Lenart A., 2016. Effect of the aerated structure on selected properties of freeze-dried hydrocolloid gels. Int. Agrophys., 30(1), 9-17.

Ciurzyńska A., Mieszkowska A., Olsiński I., and Lenart A., 2017. The effect of composition and aeration on selected physical and sensory properties of freeze-dried hydrocolloid gels. Food Hydrocolloids, 67, 94-103.

Fasogbon B.M., Gbadamosi S.O., and Taiwo K.A., 2013. Studies on the osmotic dehydration and rehydration characteristics of pineapple slices. J. Food Proc. Technol., 4, 220, doi: $10.4172 / 2157-7110.1000220$

Fu J-T. and Rao M.A., 2001. Rheology and structure development during gelation of low-methoxyl pectin gels: the effect of sucrose. Food Hydrocolloids, 15(1), 93-100.

Labbafi M., Thakur R. K., Vial Ch., and Djelveh G., 2007. Development of an on-line optical method for assessment of the bubble size and morphology in aerated food products. Food Chemistry, 102(2), 454-465.

Lewicki P.P., Witrowa-Rajchert D., and Mariak J., 1997. Changes of structure during rehydration of dried apples. J. Food Eng., 32(4), 347-350.

Martin-Esparza M.E., Escriche I., Penagos L., and Martínez-
Navarrete N., 2011. Significance of osmotic temperature treatment and storage time on physical and chemical properties of a strawberry-gel product. J. Sci. Food Agric., 91(5), 894-904.

Mc Minn W.A.M. and Magee T.R.A., 1997. Physical characteristics of dehydrated potatoes-Part II. J. Food Eng., 33, 49-55.

Nussinovitch A., Corradini M. G., Normand M.D., and Peleg M., 2000. Effect of sucrose on the mechanical and acoustic properties of freeze-dried agar, $\kappa$-carrageenan and gellan gels. J. Texture Studies, 31(2), 205-223.

Nussinovitch A., Corradini M.G., Normand M.D., and Peleg M., 2001. Effect of starch, sucrose and their combinations on the mechanical and acoustic properties of freeze-dried alginate gels. Food Res. Int., 34(10), 871-878.

Nussinovitch A. and Gershon Z., 1997. Alginate-oil sponges. Food Hydrocolloids, 11(3), 281-286.

Nussinovitch A., Velez-Silvestre R., and Peleg M., 1993. Compressive characteristics of freeze dried agar and alginate gel sponges. Biotechnology Progress, 9(1), 101-104.

Palzer S., 2009. Food structures for nutrition, health and wellness. Trends Food Sci. Technol., 20(5), 194-200.

Piotrowski D., Biront J., and Lenart A., 2008. Colour and physical proprieties of osmotically dehydrated and freeze-dried strawberries (in Polish). Żywność, Nauka, Technologia, Jakość, 4(59), 216-226.

Prothon F., 2003. Combined dehydration methods from fresh fruit to high-quality ingredients. Department of Food Engineering Lund Institute of Technology, Sweden.

Raghavan G.S.V. and Silveira A.M., 2001. Shrinkage characteristics of strawberries osmotically dehydrated in combination with microwave drying. Drying Technol., 19, 405-414

Ratti C., 2001. Hot air and freeze-drying of high-value foods: a review. J. Food Eng., 49(4), 311-319.

Sankat C.K. and Castaigne F., 2004. Foaming and drying behaviour of ripe bananas. LWT - Food Science and Technology, 37(5), 517-525.

Thibault J-F. and Ralet M-C., 2003. Physico-chemical properties of pectins in the cell walls and after extraction. In: Advances in Pectin and Pectinase Research (Eds F. Voragen, H. Schols, and R. Visser). Springer-Science+Business Media, B.V., 91-105.

Valenzuela C. and Aguilera J.M., 2013. Aerated apple leathers: effect of microstructure on drying and mechanical properties. Drying Technol., 31(16), 1951-1959.

Van Aken G.A., 2001. Aeration of emulsions by whipping. Colloids and Surfaces A: Physicochemical and Engineering Aspects, 190(3), 333-354. 